\title{
Interação academia-indústria. Relato da experiência da Vale
}

\author{
LUIZ EUGENIO A. M. MELLO ${ }^{I}$ \\ e EDGAR SARDINHA SEPÚLVEDA II
}

\section{Contexto histórico}

$\mathrm{U}$

M CONCEITO interessante sugere que as universidades (academia) têm, entre outras funções, a tarefa de produzir conhecimento. Para isso obviamente a academia usa recursos financeiros. Considerando que esses recursos são na sua grande maioria recursos públicos, conclui-se que a produção de conhecimento pela academia é financiada pelos impostos pagos pela sociedade. Assim, a alocação dos recursos públicos, pelos diferentes entes governamentais, para a produção de conhecimento é o motor principal que gera ciência e tecnologia.

Dentro dessa linha, a função das empresas, dentre outras, é de produzir riqueza. De fato, as empresas, ao produzirem produtos e serviços, entregam à sociedade riqueza, não só por tornar acessíveis esses produtos (como transformando minério de ferro e níquel em carros), mas também ao pagar salários e impostos diversos. Para produzir seus bens e serviços a indústria lança mão de tecnologia, por meio de máquinas, equipamentos e processos que em última análise foram originados na academia.

A academia e as empresas, dessa forma, são elementos críticos de um circuito em que a ciência e a tecnologia permitem às empresas produzir riqueza, que por sua vez contribuem para a produção de mais ciência e tecnologia pela academia e, consequentemente, mais riqueza pelas empresas. Essa lógica é bastante clara, já há várias décadas, para diferentes nações. Sobretudo aquelas nações desprovidas de recursos naturais ou com território restrito notabilizam-se pelo incentivo a esse encadeamento entre academia e empresas. De fato, podemos imaginar que Suíça, Cingapura ou mesmo Japão não estariam onde se encontram caso seus governantes décadas atrás não tivessem estimulado essa interação.

Em muitos casos, sobretudo no final do século XIX e início do XX, essa interação era muito mais entre duplas (universidade-indústria, por exemplo), e certamente não resultava de uma política claramente articulada. Conceitualmente esse modelo evoluiu com a proposição de uma forte interação entre academia, governo e indústria, dando origem à ideia de uma tripla hélice (ver $<$ https://triplehelix.stanford.edu/3helix_concept $>$ ). Em suas diferentes variações a interação entre esses atores (em trincas ou duplas) foi o elemento central 
para o desenvolvimento de agrupamentos industriais (clusters) e da emergência de potencialidades e forte geração de riqueza em regiões específicas.

No Brasil, um amplo conjunto de fatores contribuiu e vem contribuindo para dificultar esse processo de interação entre a academia e as empresas. O fato de nossa colonização pelos portugueses ter tido sobretudo uma natureza exploratória, visando a mera extração simples e exportação in natura ou com baixo nível processamento, contribuiu para esse processo. As guerras napoleônicas, com nossa consequente submissão à perpetuação da não industrialização (acordo de Strangford entre Portugal e Inglaterra), contribuíram em muito para manter esse perfil (Mendes Cunha; Suprinyak, 2016). Esse elemento isoladamente não justifica nossas limitações na interação academia-empresa. De fato, Cingapura, tomada aqui como um modelo de sucesso, é uma nação criada em meados do século XX. Nosso atraso histórico na industrialização, certamente contribuiu, mas sozinho não explica nossas limitações.

Nossa academia, assim como a indústria, igualmente é recente. Mais uma vez devemos às guerras napoleônicas na Europa e à vinda da família real para o Brasil a criação dos primeiros cursos superiores no país (ver <http://universidades.universia.com.br/universidades-brasil/historia-ensino-superior>). $\mathrm{O}$ atraso na criação do ensino superior e mesmo do agrupamento de instituições isoladas em universidades certamente não ajudou. Ainda assim, talvez mais importante que esse atraso, seja a natureza das instituições de ensino superior no pais. Mesmo em 2017, apesar do imenso avanço na criação de vagas pelas instituições privadas de ensino superior, é nas instituições públicas que se dá a pesquisa acadêmica no Brasil. De fato, com as honrosas exceções das instituições confessionais, notoriamente a Pontifícia Universidade Católica (PUC), possivelmente mais de 90\% da ciência produzida pela academia no Brasil sejam ainda hoje provenientes das universidades públicas. O problema principal daí decorrente é que no Brasil toda a interação de empresas com essas instituições públicas foi sempre objeto de uma série de questionamentos.

De fato, sob um viés ideológico de esquerda tivemos um impedimento que bloqueou de maneira bastante efetiva a interação entre academia e empresas no Brasil. A simultaneidade do desenvolvimento da pós-graduação no Brasil, ocorrida a partir de 1970, com o consequente forte desenvolvimento da ciência a partir daí, e dos movimentos de contestação da ditadura militar e das ideologias de esquerda, certamente limitou a interação academia-empresa. Nessa linha, interagir com empresas, ou dizendo de outra forma, interagir com o capital, significava não reconhecer o objetivo público do sistema de ensino superior. Interagir com as empresas significava vender-se ao capital e abandonar os ideais de uma sociedade mais justa.

Os diferentes obstáculos regulatórios à interação entre academia-empresa possivelmente constituíram o principal determinante do baixo nível de intensidade que ainda hoje temos nessa interação. Como consequência desses obstácu- 
los, praticamente todas as instituições de ensino superior criaram fundações de apoio. O objetivo central dessas fundações era e é justamente o de intermediar essa relação. Com diferentes níveis de sucesso e diferentes níveis de objeção por parte das diferentes instituições acadêmicas, essas fundações foram e são as grandes responsáveis pelos avanços que vimos no Brasil na construção dessa ponte (ver <http://confies.org.br/institucional>).

Além desses aspectos acima citados, diferentes outros elementos, ao longo da nossa história, devem ainda ter contribuído para a fraca interação entre academia-empresa no Brasil. Citarei apenas mais um desses elementos, a estabilidade no emprego. De fato, estando a pesquisa alocada sobretudo nas instituições públicas, a vitaliciedade da carreira de docente (aqui significando pesquisador) constituiu e constitui ainda hoje um elemento importante na minimização do fluxo de pesquisadores entre academia e indústria. Nessa mesma linha, de forma geral a academia valoriza títulos (mestrado, doutorado), enquanto a indústria valoriza capacidade de execução. Assim, um sentido sobretudo teórico se contrapõe a um sentido eminentemente prático, como se os dois não pudessem coexistir.

Nesse sentido é notável que a intenção de capacitação para a prática, que se buscava inicialmente com os mestrados profissionais, tenha progressivamente se deixado contaminar por um viés da academia (e produção de artigos). De fato, o sucesso da pós-graduação stricto sensu no Brasil terminou por hegemonicamente limitar, pelo menos nesses momentos iniciais, a implementação em um modelo próprio de formação pós-graduada de natureza mais aplicada.

\section{Inovação no setor de commodities}

As principais características das commodities são a relativa homogeneidade dos produtos e a alta escala de produção, possuindo fluxos contínuos e integrados.

Segundo Tigre (2006), a implantação de um projeto de mineração é intensa em investimento de capital e opera grandes volumes. Como resultado, o mercado de commodities é concentrado e resulta em um pequeno número de players, sendo descrito como um oligopólio homogêneo. Esse grande investimento de capital condiciona as estratégias tecnológicas, uma vez que os custos de investimento são significativos e necessitam de um longo prazo para serem integralmente amortizados.

Todas as análises realizadas por Tigre (2006) indicam que no setor de commodities há uma dificuldade na difusão de novas tecnologias, tendo em vista que essas deveriam ter como pré-requisito a complementaridade e compatibilidade com os processos de produção adotados inicialmente. Na medida em que os produtos produzidos possuem pouca diferenciação, os preços têm papel fundamental na competição entre os atores do mercado. Nesse sentido, o autor afirma que esse padrão de competição confere às inovações um viés de redução de custos, com aumento de escala produtiva, otimização de processos produtivos e redução de impactos ambientais 


\section{A Companhia Vale do Rio Doce}

Criada em 1942 como parte do esforço da guerra para prover ferro durante a Segunda Guerra Mundial, a Companhia Vale do Rio Doce (CVRD) cresceu como um dos ícones da indústria nacional. Na verdade, a CVRD foi precedida pela Brazilian Hematite Syndicate, que em 1911 deu origem à Itabira Iron Ore Company, sendo autorizada a explorar e exportar minério de ferro das jazidas de Itabira por concessão do governo federal. À mesma época, durante o XI Congresso Geológico Internacional, realizado em Estocolmo, na Suécia, em 1910, revelou-se que ali em Itabira estavam localizadas as maiores jazidas de minério de ferro do mundo.

O fácil acesso ao minério de ferro, aliado ao seu alto teor e baixa concentração de impurezas, de forma geral permitiu à CVRD trabalhar sem a necessidade de desenvolvimento técnico mais profundo, durante suas duas primeiras décadas. Em 1965, o progressivo empobrecimento do minério lavrado em Itabira levou a CVRD à criação de seu primeiro centro de pesquisa, hoje conhecido como Centro de Desenvolvimento Mineral (CDM) no município de Santa Luiza, Região Metropolitana de Belo Horizonte. For graças aos trabalhos pioneiros de pesquisa realizados no CDM que a CVRD conseguiu desenvolver uma tecnologia viabilizando técnica e economicamente a lavra e beneficiamento de um minério de ferro mais pobre, o itabirito. Foi graças a esse importante avanço tecnológico que a Vale conseguiu, na década seguinte, tornar-se o maior exportador de mineiro de ferro do mundo.

Em 1997, no processo de privatização que se desenrolava no Brasil àquela época, deu-se a privatização da CVRD e sua posterior mudança de denominação para Vale SA. Nos anos seguintes à sua privatização a Vale vivenciou simultaneamente um processo de gestão mais eficiente aliado ao espetacular crescimento da economia chinesa. No decorrer desse período a empresa ampliou sua internacionalização, marcada em 2006 pela aquisição da maior empresa de mineração do Canadá por US\$ 17 bilhões. Esse notável processo de crescimento da Vale em tamanho e complexidade teve como consequência a necessidade de reforço de certas estruturas corporativas. Incluída nessa revisão de estruturas administrativas estava a área de pesquisa e desenvolvimento.

\section{Estruturas centralizadas e distribuídas}

As organizações podem ser divididas entre administração (corporativo) e operação. Em todas as organizações há uma eterna disputa entre esses dois braços. As administrações, estruturas centralizadas, trabalham para padronizar e coordenar o trabalho, produzir relatórios, informar as autoridades e estabelecer planejamento estratégico. As operações estão voltadas para a execução direta do trabalho, buscando garantir sua replicação com o máximo de eficiência e o mínimo de alterações de rotina. $\mathrm{Na}$ indústria, as atividades de Pesquisa e Desenvolvimento (P\&D) quando executadas exclusivamente pelo corporativo frequentemente produzem trabalhos que são relegados pela operação. $\mathrm{O} P \& D$ 
centralizado tem sempre o risco de perder a conexão com as necessidades da operação. Muito mais eficiente em termos de alocação de recursos é o P\&D feito sob controle direto da operação. De forma geral, essa atividade acaba sendo muito mais de desenvolvimento que de pesquisa. As necessidades da operação são múltiplas e imediatas, fazendo que o $P \& D$ na operação tenda a perder a visão de longo prazo. As operações com frequência têm noção da importância da pesquisa de longo prazo, contudo as métricas de avaliação das operações raramente viabilizam a alocação de recursos (com disciplina) para o longo prazo.

De forma geral, nas grandes organizações industriais a multiplicidade de operações em diferentes regiões geográficas (mesmo que vizinhas) ou em diferentes negócios faz que se perca o potencial que decorre de ser grande (volume de recursos). Assim, no caso de P\&D, em uma grande empresa, a execução das atividades nas operações dá eficiência à solução dos problemas do dia a dia. Mas acaba por fazer que o resultado da grande empresa seja equivalente ao de uma empresa menor, visto que a área de P\&D da unidade operacional terá tamanho apenas equivalente ao dessa unidade. Superar o desafio de integrar os diferentes grupos técnicos e de P\&D em uma organização matricial é o elemento indispensável para uma gestão eficiente dessas atividades em uma grande organização.

\section{Modelos de inovação}

Além da divisão acima citada, é importante destacar os possíveis modelos de inovação a serem adotados pelas corporações. Henry Chesbrough (2003) é o criador da expressão Open Innovation, proposta no livro Open innovation: the new imperative for creating and profiting from technology. Na definição de Chesbrough (2003), a diferenciação entre Inovação fechada e Inovação aberta ocorre quando, basicamente, relacionamos os atores envolvidos no desenvolvimento da inovação. Assim temos:

- Inovação fechada - Processos de inovação desenvolvidos dentro de uma organização, sem envolver atores externos. Tal modelo perdurou durante quase todo o século XX e parte da premissa de que todas as pesquisas são desenvolvidas internamente e não sofrem influências de agentes externos. Desse modo, as empresas que possuem condições de investir em grandes laboratórios de P\&D têm vantagem competitiva sobre os seus concorrentes.

- Inovação aberta - Trata-se da inovação desenvolvida por meio de parcerias, compras ou licenciamento de processos de inovação, entre diferentes organizações, como empresas, universidades e indústrias. Por sua vez, assume que as organizações podem, e devem, utilizar fontes de conhecimentos internos e externos à empresa para a geração de ideias, assim como caminhos internos e externos a essa, para implementar a tecnologia desenvolvida no mercado. 
Figura 1 - Modelo de Inovação fechada e Inovação aberta

\section{Closed innovation}

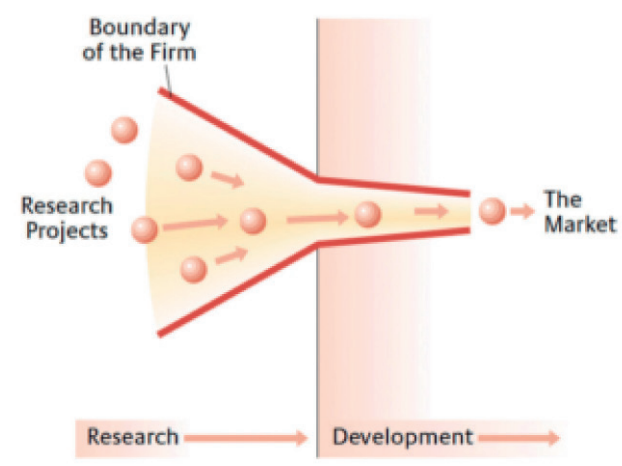

Open innovation

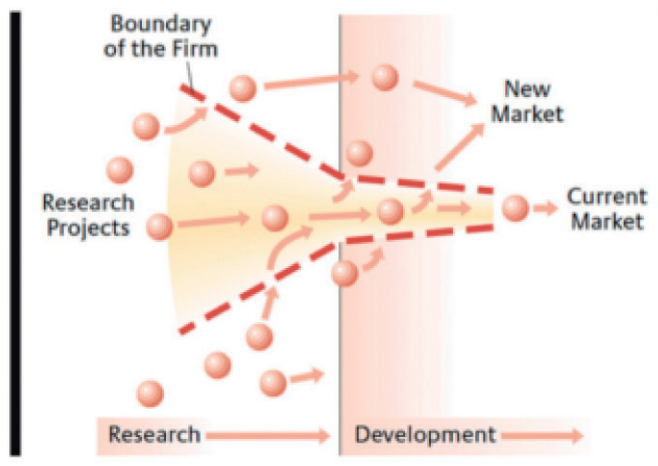

Fonte: Chesbrough (2003).

\section{P\&D e inovação na Vale}

Até a privatização em 1997, o P\&D na Vale era da incumbência do Centro de Desenvolvimento Mineral (CDM), essencialmente em um modelo de inovação fechada. A partir da privatização, teve início um processo de reorganização que incluiu tanto descentralização como centralização. A enorme expansão da Vale, por meio da aquisição de outras empresas, como Samitri em 2000, Ferteco em 2001, Caemi em 2003, Inco em 2006, dentre outras empresas, gerou ao mesmo tempo a necessidade de padronização de processos e atividades (centralização), assim como aumentou a complexidade das operações e resultou em descentralização em certas áreas.

No ano 2006, começou a amadurecer a ideia da criação de um centro de pesquisa voltado para as atividades de longo prazo, que haviam deixado de ser priorizadas em função da privatização. Além disso, mesmo que de forma não articulada pela Vale, buscava-se um modelo mais aberto de inovação e com maior fluxo de informação com atores externos à Vale. Intitulada Instituto Tecnológico Vale (ITV), essa nova unidade foi articulada em 2009, com a formalização na Vale de um departamento responsável por concretizar esse plano: o Departamento do Instituto Tecnológico Vale (DITV), hoje denominado Gerência Executiva de Tecnologia e Inovação. Ademais, a Gerência Executiva desenvolveu como outras atribuições a gestão de tecnologia e propriedade intelectual da Vale, além da articulação de parcerias de projetos de P\&D com a comunidade acadêmica e instituições de Ciência, Tecnologia e Inovação (ICT).

Dessa forma, a companhia passou a possuir duas modalidades de inovação: as necessidades imediatas ou de curto prazo, executadas de forma descentralizada pelos diferentes centros e laboratórios de pesquisa das unidades operacionais; e as atividades de P\&D que exigem tecnologias não maduras e endereçando sobretudo o médio e o longo prazos (executadas pela Gerência Executiva de Tecnologia e Inovação e ITV). 
Figura 2 - Histórico de inovação na Vale
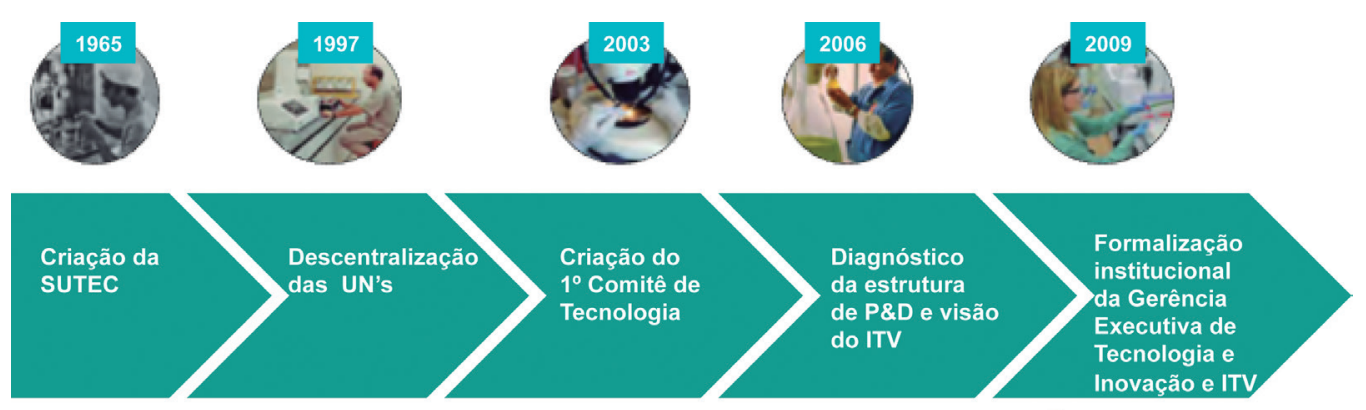

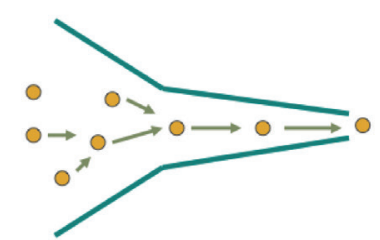

Modelo de Inovação Fechada

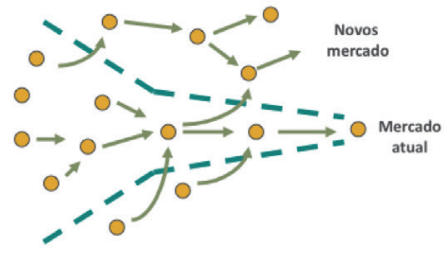

Modelo de Inovação Aberta

Fonte: Material interno, 2017.

Para a primeira modalidade, a Vale possui três grandes laboratórios, responsáveis por buscar soluções tecnológicas para o desenvolvimento de seus projetos minerais. Dois deles estão no Brasil, o Centro de Desenvolvimento Mineral $(\mathrm{CDM})$, que trabalha com várias outras atividades, como a parte de exploração, fertilizantes, cobre, outros minérios e metais, e o Centro de Tecnologia em Ferrosos (CTF), que se dedica a minério de ferro e faz algumas pesquisas associadas a manganês; e o terceiro está no Canadá, o Vale Technical Services Limited (VTSL), que tem como objetivo aumentar a vantagem competitiva dos negócios de níquel. Além dos laboratórios citados, a empresa ainda possui o Centro de Engenharia Logística (CEL) (site de inovação da empresa, 2016).

No que diz respeito ao desenvolvimento de tecnologias mais complexas, de médio a longo prazos, a Vale utiliza o modelo de inovação aberta, que coloca a empresa em contato com o conhecimento gerado pelos atores externos, por meio de parcerias com universidades e órgãos governamentais de $\mathrm{P} \& \mathrm{D}$, bem como fornecedores em geral. A coordenação dessa atuação fica a cargo da Gerência Executiva de Tecnologia e Inovação e do Instituto Tecnológico Vale (ITV).

\section{Instituto Tecnológico Vale (ITV)}

A criação do ITV como uma associação de direito privado dedicada a objetivos de ensino e pesquisa deu de partida uma identidade que a aproxima das ICT públicas no Brasil. O fato de seu quadro gestor ser constituído por pesquisadores com destacada atuação no cenário nacional de ciência e tecnologia contribuiu ainda mais para essa identidade. Por outro lado, a estreita vinculação com a mantenedora, a Vale, e o alinhamento de ambas as estratégias de atuação fizeram que o ITV claramente tivesse o reconhecimento necessário à sua manu- 
tenção. Em teoria, a pesquisa executada no ITV poderia ser sempre realizada com a participação de diferentes parceiros externos na academia e em prestadores de serviço e fornecedores diversos. Contudo, atividades mais sensíveis e de natureza confidencial, assim como a apropriação do conhecimento pela própria Vale e um maior controle sobre a execução dos projetos são todos elementos difíceis de gerenciar externamente. Assim, o ITV constituiu e constitui um importante elemento de ligação com o mundo externo à Vale. De fato, a criação do ITV, ainda que resultando na nucleação de grupos internos de pesquisa, contribuiu para a ampliação do leque de colaborações da Vale com parceiros externos.

Constituído legalmente em 2010, o ITV tem como objetivo a produção de pesquisas e o desenvolvimento econômico de base tecnológica, além da geração e difusão de novos conteúdos voltados para o desenvolvimento sustentável e à cadeia da mineração do futuro, levando a Vale a superar os padrões consagrados de excelência em pesquisa e desenvolvimento. Atualmente, o Instituto Tecnológico Vale atua em duas unidades, localizadas no Brasil: a unidade de Ouro Preto, Minas Gerais, especializada em temas de Mineração; já a unidade de Belém, no Pará, prioriza as pesquisas em Desenvolvimento Sustentável.

Com a criação do ITV a Vale passou a fazer uso do sistema de bolsas de pesquisa para execução de suas atividades. Trabalhando dentro dos modelos disponíveis no sistema nacional de ciência e tecnologia e em parceria com CNPq e Capes, o ITV contribuiu de forma notável para a alocação de pesquisadores bolsistas para temas de interesse da Vale. O grande viés academicista da pesquisa, tão criticado no país, deu lugar a um viés de pesquisa com clara aplicação.

Para uma empresa com atividades na floresta amazônica, a insuficiência do conhecimento cientifico é um sério entrave à sua atuação. A Vale, em decorrência de seus interesses comerciais, protege uma área de mais de oito mil quilômetros quadrados de floresta para um uso de $4 \%$ desse território para a mineração em si. Ainda assim, mesmo nessa área relativamente pequena, com relação ao total protegido, há que considerar as diferentes questões ambientais, como a ocorrência de espécies endêmicas ou ameaçadas. Para evoluir nesse assunto, o ITV liderou uma colaboração com o Museu Paraense Emilio Goeldi e dezenas de outras instituições de pesquisa, que resultou na publicação da Flora de Carajas (Viana et al., 2016). Assim, o mapeamento detalhado de cerca de 700 espécies botânicas não apenas gerou conhecimento de base, mas também deu os alicerces para uma atividade industrial de forma racional.

Muitas foram as dificuldades associadas à criação do ITV. Confiança talvez seja a palavra que sintetiza essas dificuldades. De parte da comunidade acadêmica, de onde vieram os primeiros pesquisadores, a ausência de um modelo de referência mais familiar dificultava o entendimento do que estava sendo proposto. Assim, o núcleo inicial de pesquisadores possivelmente tenha se constituído de pessoas com mais disposição para o novo e abertas em certa medida ao risco. Outro ponto importante é a ausência de estabilidade no emprego, característica 
básica da iniciativa privada. Aliado ao item anterior, essa característica resultou na imensa dificuldade inicial de contratarmos pesquisadores em estágios intermediários da carreira. Assim, a densidade inicial dos grupos de pesquisa dependeu da disponibilidade de pesquisadores já consolidados e com pouco a perder caso a iniciativa falhasse. Também a ausência de uma tradição mais consolidada em ciência e tecnologia foi um obstáculo inicial importante. A contraposição a isso decorreu do nome da empresa mãe, a Vale.

Dentre as dificuldades sob a perspectiva interna estava, e de certa forma sempre estará, o desafio de conectar atividades de longo prazo com as necessidades da empresa. De fato, a principal razão de insucesso de diferentes centros corporativos de P\&D resulta dessa desconexão. Quanto a corporação paga a conta, frequentemente a operação acaba sendo de certa forma ignorada. No estereótipo máximo desse modelo os cientistas de P\&D corporativo tratam os engenheiros e técnicos da operação como toupeiras que não veem um palmo à frente do nariz. De seu lado, engenheiros e técnicos da operação enxergam aqueles cientistas como lunáticos descolados da realidade e que torram os recursos da empresa em projetos inúteis, que ninguém pediu e que são impraticáveis (Buderi, 2000).

Estabelecer a confiança tanto interna como externamente é um elemento critico na materialização de qualquer parceria. A superação dos preconceitos de ambas as partes e o entendimento das limitações e das aspirações de ambos os lados foram uma etapa central nesse processo de criação do ITV.

\section{Atuação da Vale na interação academia-indústria}

A elaboração de editais conjuntos com as fundações de apoio à pesquisa dos estados de Minas Gerais (Fapemig), Pará (Fapespa) e São Paulo (Fapesp) foi um outro importante instrumento de consolidação dessa estratégia de inovação aberta. Igualmente assinado em 2009 e com um montante de recursos de R\$ 120 milhões (em sua modelagem inicial), essa constituiu-se na maior iniciativa de fomento à pesquisa articulando uma rede de fundações de apoio e uma empresa no país. Os objetivos do projeto incluíam não apenas a execução de projetos de pesquisa em temáticas de interesse da Vale, mas também a articulação de redes de pesquisadores entre essas três unidades da federação. Esse edital resultou no apoio a mais de cem projetos de pesquisa, redundando em centenas de bolsas de pós-graduação associadas. Em algumas áreas do conhecimento, como a engenharia elétrica, esse edital triplicou o número de bolsas de pós-graduação concedidas no estado do Pará. Assim, o potencial de transbordamento desse edital manifestou-se também com a capacitação e consolidação de grupos em regiões tradicionalmente com menor acesso a recursos externos.

Um dos objetivos daquele primeiro edital era também o de criar as bases para potenciais colaborações com as próprias unidades do ITV. Em paralelo, além de um movimento onde de forma aberta foram solicitadas proposta de projetos de pesquisa em temas de interesse da Vale, buscou-se também mapear 
instituições especificas para em projetos bem definidos atender demandas da empresa.

Durante a execução e acompanhamento dos projetos de pesquisa junto à Vale ficou patente a diferença entre o modus operandi da academia e o da empresa. Para viabilizar essa interação foi fundamental a existência de um mediador interno (nesse caso, a Gerência Executiva de Inovação e Tecnologia) para o alinhamento e condução da relação. Exemplos dos entraves são a documentação exigida para o processo de liberação de acesso as áreas operacionais, exigências para acesso com automóveis, indisponibilidade de paralização de operações, entre outros. Em qualquer empresa a entrada de pessoas não treinadas em uma operação representa um risco aumentado para a segurança física das pessoas. $\mathrm{Na}$ vigência desses projetos deu-se uma das maiores mudanças de cultura da Vale em termos de saúde e segurança. A compatibilização entre a execução dos projetos e a plena aderência ao valor número 1 da Vale, "a vida em primeiro lugar" não foi trivial. Em retrospecto, a ausência de um único acidente significativo na execução de centenas de projetos de pesquisa em diferentes áreas industriais e de risco foi um importante marco para a Vale.

A transferência dos resultados para a Vale tampouco foi um processo natural. De fato, foi o acompanhamento próximo da Gerência Executiva de Inovação e tecnologia que garantiu a transferência de conhecimento técnico cientifico e resultados de forma significativa e não apenas esporádica e pontual para a empresa como um todo. A parceria rendeu bons frutos no que diz respeito à formação de recursos humanos, publicação de artigos em revistas especializadas, desenvolvimento de protótipos e metodologias, entre outros avanços tecnológicos. Em todo o histórico da parceria, empregados das áreas de meio ambiente, saúde \& segurança, cobre, fertilizantes, logística, TI, RH e de ferrosos passaram a interagir ativamente, em uma parceria inédita no país, quer em termos de numero de pessoas envolvidas, quer em termos do volume de recursos aportados em uma única chamada.

Como elementos para reflexão estão a não observância de regras acordadas em contrato por parte da academia. Para a Vale, como para qualquer empresa, o potencial de patenteamento ou de proteção de uma descoberta deve ser sempre considerado. Assim, o contrato assinado pelos pesquisadores e endossado pelos dirigentes de suas instituições definia que antes de qualquer publicação a Vale receberia os manuscritos para análise, e haveria um prazo de no máximo 60 dias para manifestações de parte da Vale quanto a eventual interesse em patenteamento por exemplo. Sob esta óptica o edital foi um fracasso, visto que giram em torno de $10 \%$ para menos os casos em que os pesquisadores observaram essa regra, com a qual eles mesmos haviam se comprometido. $\mathrm{O}$ fato de a maioria dos projetos se enquadrarem no que é denominado estágio pré-competitivo fez que não houvesse maiores problemas em decorrência da não observação dessa cláusula. 
Essas ações reposicionaram a Vale ante os atores da tripla hélice (Empresa; Universidades e ICT; e Órgãos Governamentais), uma vez que a estrutura criada transita pelos interesses e atua como um facilitador para esses atores. Conforme representação da Figura 3.

Figura 3 - Modelo de articulação entre a Vale e atores externos

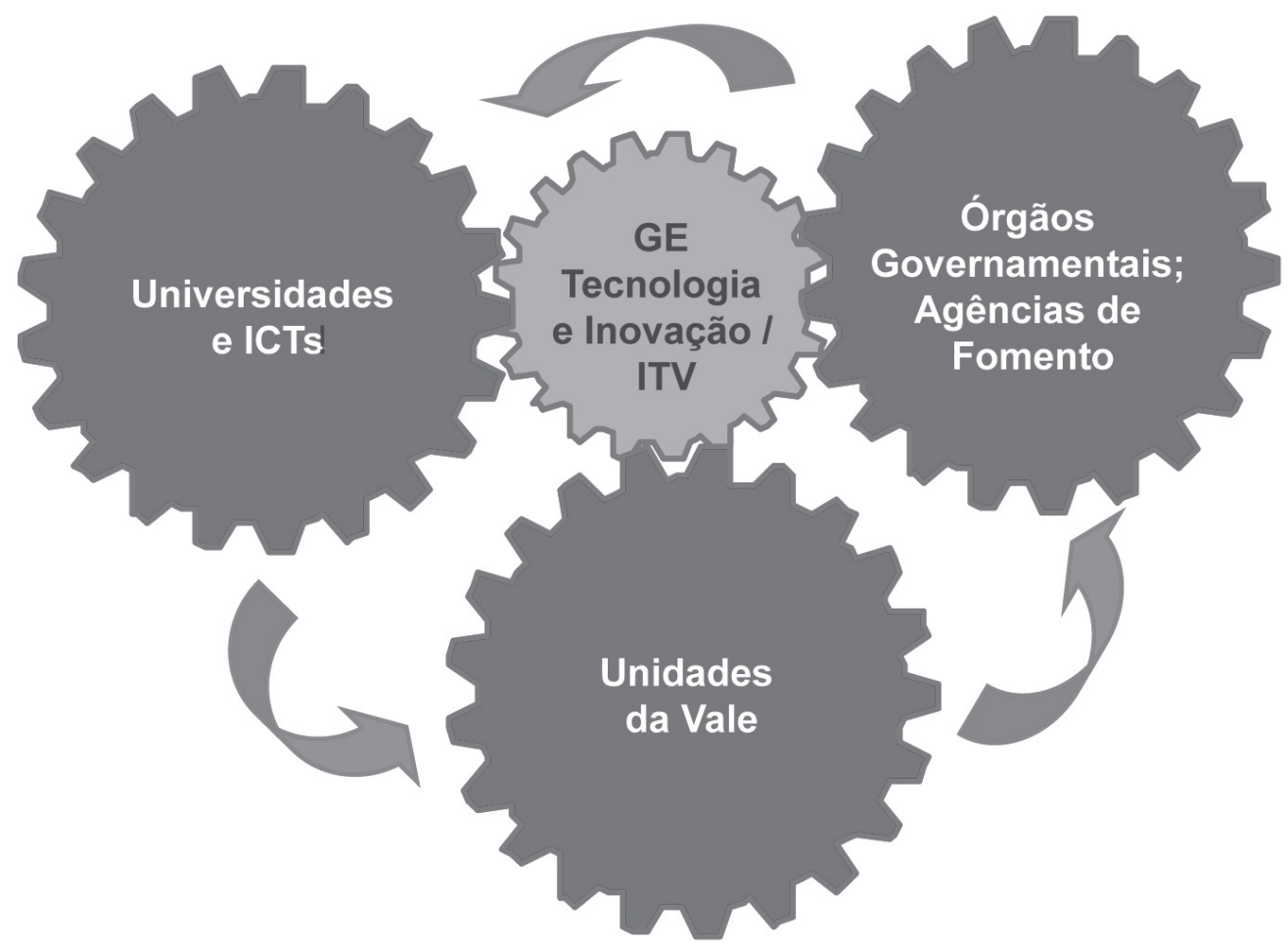

Fonte: Material interno, 2017.

Em uma visão complementar dessa engrenagem, ressalta-se que esse modelo de atuação desenvolve múltiplas possibilidades de entrada e saída de tecnologias no funil da inovação, ou seja, as fontes de inputs e outputs tecnológicos a serem trabalhados. Por sua vez, essas fontes externas podem ser oriundas de universidades, instituições de pesquisa, empresas parceiras, fornecedores, startups etc. Além disso, a Gerência Executiva e o ITV se relacionam com um outro grande número de atores internos à Vale, principalmente áreas operacionais, para a articulação e gestão de projetos de P\&D. Superar o desafio de integrar os diferentes grupos técnicos e de P\&D em uma organização matricial é o elemento indispensável para uma gestão eficiente dessas atividades em uma grande organização.

Por fim, por se tratar de uma estrutura corporativa, atuando no modelo de inovação aberta, a manutenção de uma visão de longo prazo ante o desenvolvimento de P\&D é garantida. Não focando nas soluções imediatas e de desafios de curto prazo das áreas operacionais. 
Em resumo, todos esses fatos e iniciativas buscam a redução das barreiras existentes na relação entre universidades (meios de produção de conhecimento) e empresas (produtoras de riquezas), tendo em vista todas as dificuldades existentes entre os diversos históricos e interesses de atuação. A criação do ITV inspirou-se nos grandes centros corporativos de P\&D que tiveram seu apogeu no século XX. Instituições notáveis como Bell Laboratories da ATT ou Palo Alto Research Center da Xerox foram um marco da atividade de P\&D na indústria. A proposta de recriação desse modelo (com adaptações) no Brasil do século XXI, no momento em que ele parece dar seus últimos suspiros nos Estados Unidos, é cabível em face do grau de atraso de alguns fundamentos em nosso país. Nossos níveis de educação (tanto alfabetização como matriculas no ensino superior) e consequentemente tudo que dai decorre se assemelham aos dos Estados Unidos do início do século XX. Acreditamos que a disponibilidade de recursos humanos qualificados, da experiência histórica em outros países e a disposição para interação de parte da academia tenham finalmente criado as condições em que um modelo como esse possa florescer no Brasil.

\section{Referências}

BUDERI, R. Engines of tomorrow: How the worlds best companies are using their research labs to win the future. New York: Simon and Schuster, 2000.

CHESBROUGH, H. Open innovation: the new imperative for creating and profiting from technology. S. 1.: HBS Press, 2003.

Open innovation: researching a new paradigm. Oxford: s. n., 2006.

MENDES CUNHA, A.; SUPRINYAK, C. E. The political economy of Latin American independence. London: Routledge; Taylor \& Francis Group, 2017.

TIGRE, P. B. Gestão da inovação: A economia da tecnologia no Brasil. Rio de Janeiro: Elsevier, 2006.

VALE. Inovação. Nossos Centros de Pesquisa. Disponível em: <http://www.vale.com/ brasil/PT/initiatives/innovation/itv/Paginas/default.aspx>. Acesso em: 23 out. 2015

VIANA, P. L. et al. Flora das cangas da Serra dos Carajás, Pará, Brasil: história, área de estudos e metodologia. Rodriguésia, v.67, n.5, p.1107-24, 2016. Disponível em: <https://dx.doi.org/10.1590/2175-7860201667501>.

RESUMO - Abordamos aqui a nucleação de um modelo de inovação aberta na Vale (uma das maiores mineradoras do mundo) apresentando o contexto histórico em que se deu esse processo. Discutimos algumas das questões que possivelmente haviam até então dificultado a implantação de uma estrutura de pesquisa e desenvolvimento focando o longo prazo pela indústria no Brasil. Destacamos algumas das dificuldades encontradas ao longo do processo, bem como algumas das razões que levaram ao sucesso da iniciativa. PALAVRAS-CHAVE: Inovação aberta, Tripla Hélice, Interação academia-indústria, Pesquisa e desenvolvimento, Desenvolvimento tecnológico. 
ABSTRACT - We discuss how Vale (one of the world's largest diversified mining companies) implemented an organizational structure that enabled an open innovation model. We describe the historical perspective in which this process took place. In addition, we present some of the potential causes underlying the slow advance of Brazilian industry in undertaking long-term research and development agendas. Lastly, we list some of the obstacles encountered in this process, as well as some of the potential reasons that might have contributed to the success of the initiative.

KEYWORDS: Open innovation, Triple Helix, Academy-industry partnerships, Research and development, Technological development.

Luiz Eugenio A. M. Mello é professor do Departamento de Fisiologia da Universidade Federal de São Paulo, gerente executivo de Inovação e Tecnologia, Vale SA.

@ - lemello@unifesp.br / luiz.mello@vale.com

Edgar Sardinha Sepúlveda é gerente executivo de Inovação e Tecnologia, Vale SA. @ - edgar.sepulveda@vale.com

Recebido em 12.7.2017 e aceito em $1^{\circ} .8 .2017$.

${ }^{\text {I } D e p a r t a m e n t o ~ d e ~ F i s i o l o g i a, ~ U n i v e r s i d a d e ~ F e d e r a l ~ d e ~ S a ̃ o ~ P a u l o, ~ S a ̃ o ~ P a u l o, ~ S a ̃ o ~ P a u l o, ~}$ Brasil.

II Gerência Executiva de Inovação e Tecnologia, Vale SA, Rio de Janeiro, Brasil. 